\title{
Equatorial
}

v.7 n.12 | jan/jun 2020

ISSN: $2446-5674$

Dossiê: Gênero, deslocamentos e fronteiras no/do mundo contemporâneo

\section{Ser mulher Karipuna e outras subjetividades em contexto de deslocamento entre a aldeia em Oiapoque e o espaço urbano belenense}

\author{
Ana Manoela Primo dos Santos \\ Mestranda em Sociologia e Antropologia - UFPA
}

\section{RESUMO}

Este artigo trata da questão sobre os primeiros indígenas Karipuna do Amapá a saírem das aldeias com vistas a se inserirem nos ensinos secundário e de nível superior terem sido mulheres, filhas de uma liderança indígena local. Construiu-se, a partir disso, uma reflexão sobre as formas de protagonismo da mulher Karipuna, assim como sobre a possibilidade de se vivenciar o parentesco e a territorialidade indígena em meio aos contextos de deslocamento urbano. Houve também uma reflexão sobre por qual motivo, atualmente, nós indígenas sentimos a necessidade de nos inserirmos em uma educação institucional ao mesmo tempo em que vivenciamos e priorizamos a educação indígena. Ressalte-se que a autora é mulher do povo Karipuna, que vivencia junto às suas parentas os processos apresentados.

Palavras-chave: Karipuna do Amapá; Mulheres indígenas; Etnologia indígena; Território indígena; Educação com povos indígenas. 


\title{
Being a Karipuna woman and other subjectivities in the context of displacement between the village in the Oiapoque and the belenense urban space
}

\begin{abstract}
This article deals with the issue that the first Karipuna of Amapá indigenous people leaving the villages with a view to insert themselves into secondary and higher education were women, the daughters of a local indigenous leader. Based on this, it also offers a reflection on the forms of protagonism of the Karipuna woman, as well as on the possibility of experiencing kinship and indigenous territoriality in the context of urban displacement. There is also a reflection on why, today, we indigenous people feel the need to insert ourselves in an institutional education at the same time that we experience and prioritize indigenous education. It is noteworthy that the author is a woman of the Karipuna people, who experience with her relatives the processes presented.
\end{abstract}

Keywords: Karipuna of Amapá; Indigenous women; Indigenous ethnology; Indigenous territory; Education with indigenous people.

\section{Ser mujer Karipuna y otras subjetividades em el contexto del desplazimiento entre el Pueblo en Oiapoque y el espacio urbano belenense}

\section{RESUMEN}

Este artículo aborda el tema de los primeros indígenas Karipuna do Amapá que abandonaron las aldeas con el fin de insertarse en la educación secundaria y superior que eran mujeres, las hijas de un liderazgo indígena local. En base a esto, una reflexión sobre las formas de protagonismo de la mujer Karipuna, así como sobre la posibilidad de experimentar parentesco y territorialidad indígena en el contexto del desplazamiento urbano. También hay una reflexión sobre por qué, hoy en día, los indígenas sentimos la necesidad de insertarnos en una educación institucional al mismo tiempo que experimentamos y priorizamos la educación indígena. Observando que la autora es una mujer del pueblo Karipuna, que experimenta los procesos presentados con sus familiares.

Palabras clave: Karipuna de Amapá; Mujeres indígenas; Etnología indígena; Territorio indígena; Educación con los pueblos indígenas. 


\section{Introdução: considerações iniciais sobre os contextos}

Antes de adentrar nas descrições e discussões do que proponho para este artigo, que no caso são: 1) as questões pertinentes ao fato de que os primeiros indigenas Karipuna do Amapá a sairem das aldeias com vistas a se inserirem nos ensinos de nivel secundário e superior foram mulheres, filhas de uma liderança indigena local; 2) sobre o que significon e o que significa o território ao longo desse processo de deslocamento, que tem como foco a passagem entre a aldeia em Oiapoque e o espaço urbano belenense; 3) assim, como por qual motivo, atualmente, nós indigenas, sentimos a necessidade de nos inserirmos em uma educação institucional, que em muitos aspectos se difere da educação indígena; é imprescindível que se teçam algumas considerações que esclareçam "Quem é o povo Karipuna do Amapá?", algo que caberá à próxima seção, para que assim se possa adentrar nas três questões apresentadas. Declaro também que a autora deste artigo é uma mulher indígena do povo Karipuna e que esta se enquadra no contexto de deslocamento que aqui será expresso, questões que se tornarão mais claras ao longo da leitura.

\section{O Povo Karipuna do Amapá}

O povo indígena Karipuna do Amapá ${ }^{1}$ conta com uma população próxima a 2.920 pessoas $^{2}$, que em sua grande maioria vivem em vinte e uma aldeias localizadas nas Terras Indígenas Uaçá, Galibi e Juminã, situadas no extremo norte do estado do Amapá, no município de Oiapoque, região de fronteira entre o Brasil e a Guiana Francesa. Em meio às Terras Indígenas, compartilhamos nosso território com outros três povos: os Palikur (aruak), os Galibi Marworno (karib) e os Galibi Kalinã (karib) ${ }^{3}$. Juntos compomos o grupo povos indígenas de Oiapoque, com 39 aldeias e cerca de sete mil indígenas (SANTOS, MACHADO, 2019; SILVA, COSTA, ESTEVES, 2017. p. 5).

Nós, os Karipuna, somos de origem tupi (NIMUENDAJÚ, Apud Capiberibe, 2001. p. 86), porém, de acordo com pesquisas de Expedito Arnaud (1970, p. 2), com o passar do tempo fomos "nos esquecendo de nossa língua original" e nos tornamos falantes da língua patuát, uma língua creoula, que é uma mistura de tupi e karib com a língua francesa. Este esquecimento referido por Arnaud é uma metáfora que suaviza os processos de colonização francês e português pelo qual passamos e que extinguiu parte de nossa língua original, restando-nos apenas fragmentos que compõem o já mencionado patuá. Atualmente, além do patuá, falamos também as línguas portuguesa e francesa (esta última por conta da fronteira). Em nossa organização social, nos dividimos 
em famílias; praticamos casamentos endogâmicos (dentro das famílias) e exogâmicos (para além das famílias, ainda no nível do grupo, mas também com outros povos indígenas e até com não indígenas); nossa descendência é cognata bilateral (matrilinear e patrilinear); e nossa cosmologia abarca elementos do catolicismo que se mesclam a aspectos do xamanismo (ARNAUD, 1970, 1991; SOARES, 2018a; TASSINARI, 2003).

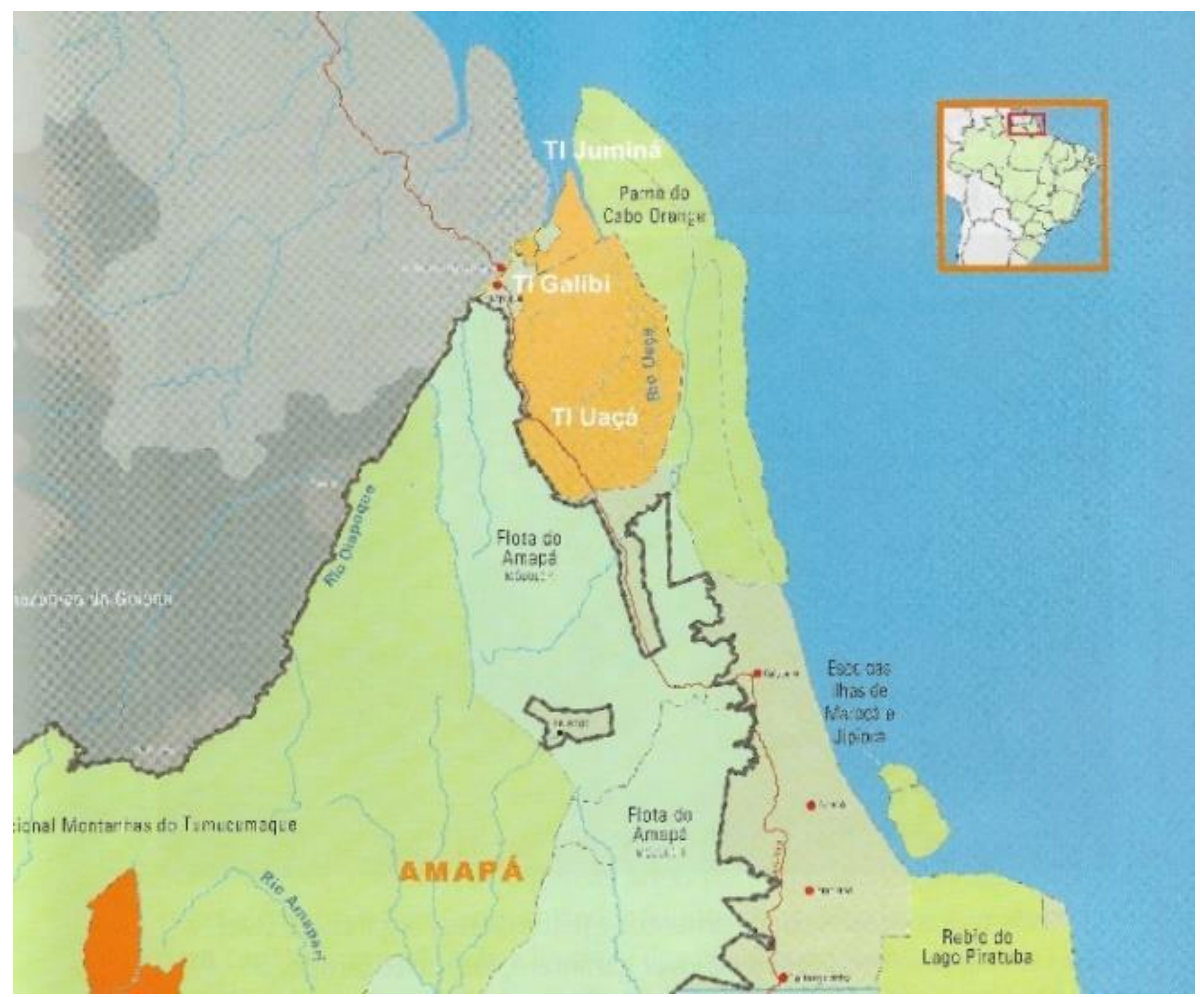

Figura 1: Localização das Terras Indígenas Uaçá, Galibi e Juminã. Fonte: Mapa das Terras Indígenas do Brasil em 2016 do Instituto Sócio Ambiental. Disponível em: https://www.socioambiental.org/pt-br/mapas. Acesso em 14 de mai. de 2019.

Estes dois parágrafos sobre os aspectos mais gerais de meu povo foram inclusos para que o leitor se situe, ainda que superficialmente, sobre algumas de nossas características principais, como nossa posição geográfica, a interação com outros povos indígenas da região, nossa origem linguística, organização social e religião. Como alguém que além de Karipuna ocupa também a posição de antropóloga, creio ser relevante estabelecer uma apresentação sobre o povo com o qual se propõe dialogar. Esta é a minha sobre meu povo de origem e com o qual teço pesquisas colaborativas. Não pretendo me adentrar de modo mais intenso sobre o que já foi dito sobre nós nos parágrafos anteriores, eles são apenas para que o leitor tenha uma breve noção de quem somos. Porém, agora torna-se imprescindível que se passe às questões que de fato me proponho a discutir. 


\section{Ser mulher Karipuna do Amapá e outras subjetividades antropológicas: Deslocamentos entre a aldeia em Oiapoque e o espaço urbano belenense}

Neste artigo, na posição de mulher Karipuna, estou a escrever sobre uma perspectiva subjetiva sobre os deslocamentos de algumas das mulheres de meu povo. Situo estes movimentos em dois contextos distintos. No primeiro, discorro sobre o deslocamento da indígena Karipuna Suzana Primo dos Santos, desde suas vivências na aldeia Santa Isabel, que se localiza na Terra Indígena Uaçá (Oiapoque - AP), até a sua ida para a cidade de Belém, capital do estado do Pará. Também trato do fato de que seu percurso está em profunda conexão com os deslocamentos de suas irmãs, também indígenas Karipuna, pelos mesmos espaços. Considera-se também que Suzana presenciou o período em que muitas indígenas se deslocavam para Belém, para cursarem a escola e o nível superior, e que atualmente elas se deslocam apenas pelo segundo motivo ou para realizarem algum tratamento de saúde em casos mais extremos que não podem ser tratados no Amapá ou para visitarem parentes que estão em Belém. Assim, as primeiras indígenas Karipuna a adentrarem no espaço urbano belenense foram respectivamente as irmãs de Suzana: Vitória, Isabel, depois a própria Suzana e posteriormente Estela.

$\mathrm{Na}$ segunda parte, trato da extensão da continuidade do deslocamento de Suzana através de mim, pois, minha relação de parentesco com ela é direta e extremamente próxima: Suzana é minha mãe. Aqui, trato do fato, ainda que metafórico, de ter sido deslocada antes mesmo de meu nascimento para Belém, crescendo nesta cidade como uma indígena que possui aldeia, mas que pelas vicissitudes da vida foi criada como indígena urbana. Agora, pratico um retorno à Santa Isabel, através de experiências antropológicas, pois, atualmente, sou estudante de antropologia no mestrado do Programa de Pós-Graduação em Sociologia e Antropologia da Universidade Federal do Pará (PPGSA / UFPA).

Nas considerações finais, trago uma reflexão sobre os dois contextos apresentados, aliada a ponderações sobre o protagonismo feminino, a ressignificação da territorialidade, a importância dos processos educacionais, os racismos e as múltiplas lutas que nós povos indígenas enfrentamos.

Imprime-se aqui uma metodologia auto antropológica e auto etnográfica (RAPPAPORT, 2007, 2018; STRATHERN, 2015), visto que estou a fazer uma reflexão sobre meu povo. Portanto, tal pesquisa é subjetiva e se caracteriza como um olhar para 
si: um olhar para mim enquanto Karipuna e pesquisadora, o que perpassa por elementos biográficos, mas principalmente um olhar para meu povo. Este é um processo colaborativo entre mim e as outras pessoas que são Karipuna, visto que o conhecimento indígena não é algo individual, mas sim um processo de construção coletiva, pois, o que há aqui são as nossas vivências e diálogos. Sendo assim, as principais formas de obtenção e análise de informações foram as convivências cotidianas com os parentes ${ }^{6}$ Karipuna, entrevistas, gravações em áudio, uso do diário de campo e a leitura da bibliografia antropológica já produzida sobre nós.

Ressalte-se também que aqui não pretendo adentrar em deslocamentos a nível macro, mas sim estar a um nível micro dos mesmos (SIMMEL, 2006), como explicarei melhor adiante, sendo que as questões aqui expostas estão relacionadas ao gênero e às feridas coloniais (MALDONADO-TORRES, 2007; MIGNOLO, 2007; QUIJANO, 2011). 


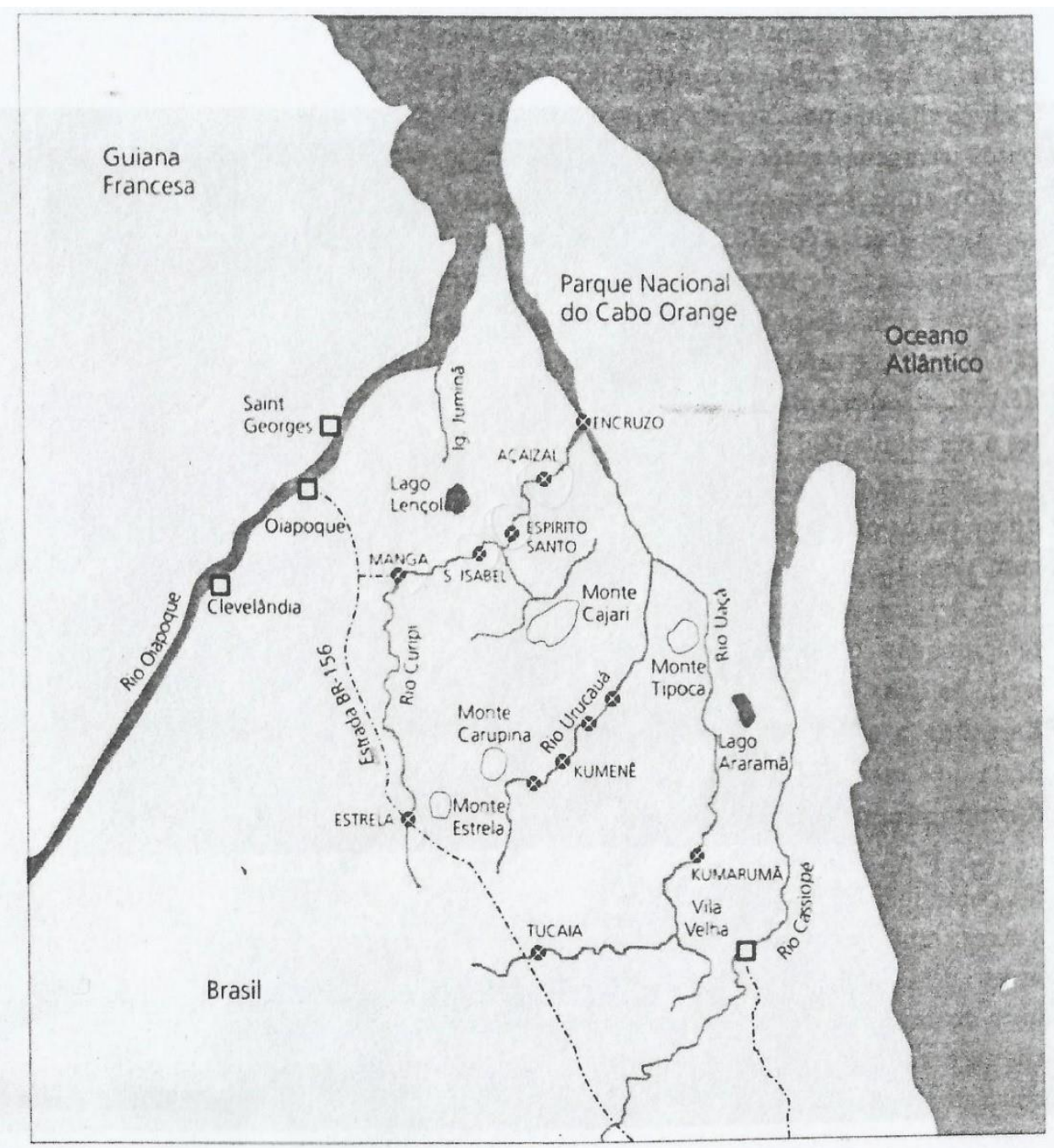

Figura 2: Mapa com algumas das aldeias dos povos indígenas de Oiapoque. Retirado do livro O Bom da Festa: o processo de construção cultural das famílias Karipuna do Amapá, de Antonella Tassinari (2003). Nele, é possível verificar a localização da aldeia Karipuna Santa Isabel, que está entre as aldeias Manga e Espírito Santo, ambas também Karipuna.

\section{As primeiras mulheres indígenas de Oiapoque a se deslocar}

Quando a antropóloga Eneida Correa de Assis passou a realizar pesquisas com os povos indígenas de Oiapoque, nos anos 1970, relatou, ao rememorar tal época através de seus diários de campo, que durante seus primeiros momentos de pesquisa não costumava prestar muita atenção em quem eram as mulheres Karipuna, Palikur e Galibi Marworno, concentrando-se mais sobre os homens como protagonistas de tais povos. Porém, após algum tempo, Assis passou a refletir sobre quem elas eram, reparando que tais mulheres possuíam seus protagonismos, mas que ao mesmo tempo também possuíam um comportamento que ela classificava como muito tímido e retraído (ASSIS, 2012), devendo a esta atitude comportamental a justificativa de não ter voltado seus 
olhos imediatamente para quem elas eram. Tais comportamentos são sempre lembrados a mim por minha mãe, Suzana, para que eu compreenda como eram as mulheres de nosso povo antigamente. Porém, é exatamente neste período, em que as mulheres Karipuna eram mais reservadas (principalmente com relação ao ato da fala, pois se comunicavam mais com as pessoas indígenas já que falavam mais o patuá do que o português ${ }^{7}$ ), que se inicia o processo de deslocamento delas para fora das aldeias e isto está diretamente relacionado aos processos educacionais presentes em nosso povo (ASSIS, 1981).

Durante a década de 1940, o indígena Karipuna Manoel Primo dos Santos, mais conhecido como cacique Côco, fundou, junto à sua primeira esposa, Delfina dos Santos Batista, uma indígena Karipuna e de descendência Palikur, a aldeia Santa Isabel (TASSINARI, 2003) ${ }^{8}$. Influenciado pela educação institucional que se consolidava na aldeia que fundara (ASSIS, 1981), decidiu que seus filhos e filhas deveriam estudar e se possível prosseguir os estudos o máximo que pudessem, nem que isto significasse se deslocar para além da aldeia. Dentre os filhos que tiveram esta oportunidade, estavam as filhas mais velhas. Vitória, Isabel ${ }^{9}$, Suzana e Estela foram as primeiras mulheres indígenas Karipuna a residirem fora da aldeia em consequência dos estudos. Saíram de Santa Isabel com esta finalidade e em meio a este processo passaram pelos espaços urbanos de Oiapoque - AP, Macapá - AP e Belém - PA; porém, dentre estas quatro mulheres, irei me debruçar especificamente sobre a trajetória de deslocamento de Suzana. 


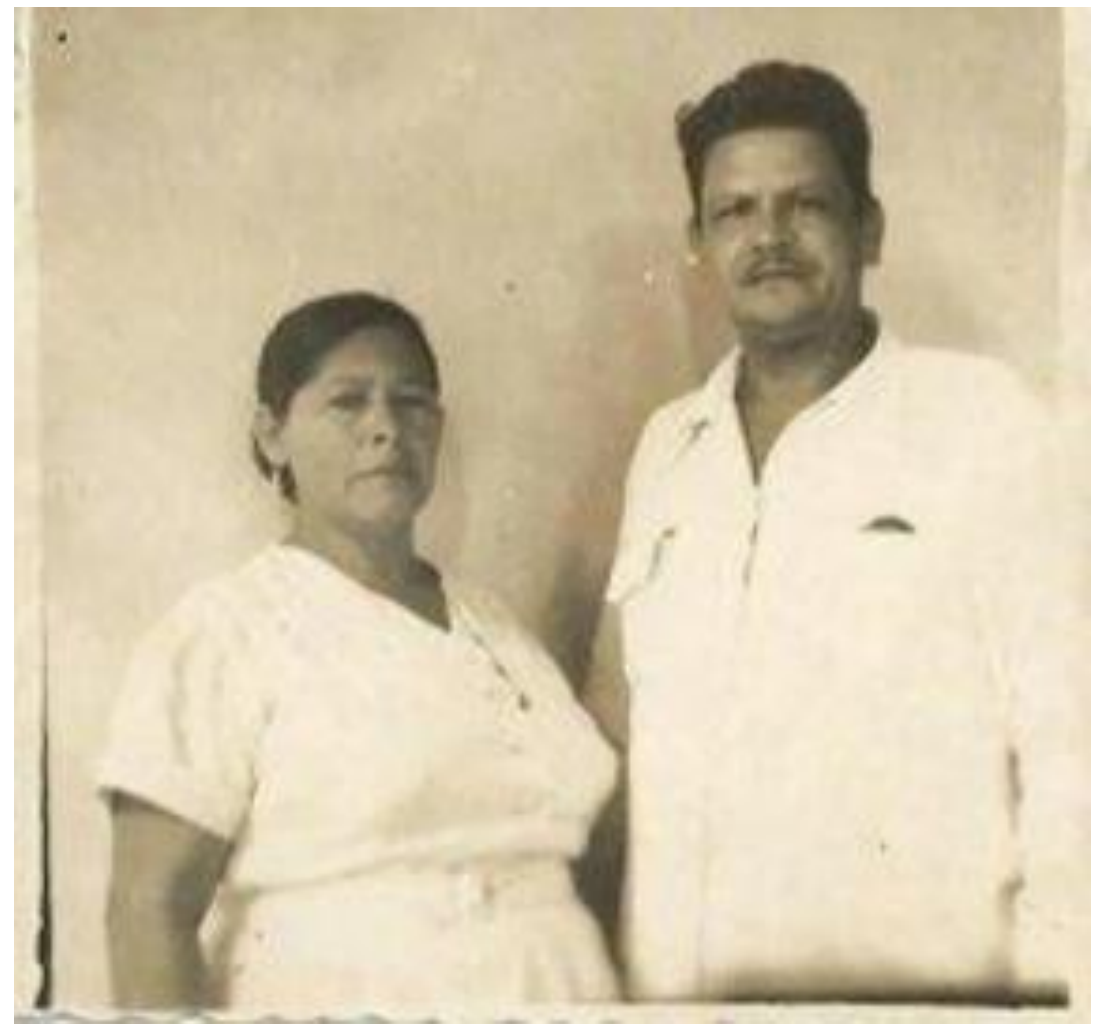

Figura 3: O cacique Côco e sua esposa Delfina, fundadores da aldeia Santa Isabel. Fonte: Arquivo do Cimi/Norte (SANTOS SILVA, CUNHA, 2018).

Suzana nasceu em 14 de fevereiro de 1954, em Santa Isabel (T.I. Uaçá, Oiapoque - AP) e como assinala Zorzetto (2018):

Viveu com seu povo até os 17 anos e aprendeu com a mãe a fazer grafismos em cuias usadas para produção e consumo de alimentos e bebidas. Mudou-se para Belém nos anos 1970 para completar o segundo grau (atual ensino médio) e, mais tarde, cursou Ciências Sociais na Universidade Federal do Pará. (ZORZET'TO, 2018).

Desde o ano de 1934, período anterior a criação da aldeia Santa Isabel e ao próprio nascimento de Suzana e de suas irmãs, já havia uma escola entre os Karipuna, criada na aldeia Espírito Santo (que é cerca de dez minutos de distância de Santa Isabel) pelo governo do interventor federal do Pará, na época o cel. Magalhães Barata. Em 1945, esta escola foi desativada e transferida para a recente aldeia de meus avós, porém nesta época, entre os povos indígenas de Oiapoque, a escola abrangia apenas o ensino primário: aprendia-se a ler, escrever e contar (RONDON, 2019; TASSINARI, 2003). Por isso, meu avô incentivou as filhas a darem prosseguimento aos estudos no ambiente externo à aldeia. 
Suzana relata que teve dificuldades de aprendizagem e permanência durante o período da escola; conta que quando saiu da aldeia fazia algumas das séries, mas que depois voltava a morar na aldeia, retornando posteriormente para fazer mais algumas séries escolares e depois novamente para lá, o que criava lacunas em sua vida estudantil, pois, a intenção de seu pai era que retornasse para a aldeia apenas nas férias. Primeiro, foi estudar em Oiapoque (parte urbana do município) e após isto em Macapá - AP, concluindo o Ensino Médio ao se mudar para Belém, no extinto Colégio Rui Barbosa.

Ingressou no curso de Ciências Sociais da Universidade Federal do Pará (UFPA) entre os anos de 1982 e 1983 (não há um consenso sobre o ano exato), concluindo o mesmo no ano de 1991. Sua graduação, assim como sua passagem pela escola, foi prolongada por inúmeros fatores, estando entre os principais os de que Suzana tinha de trabalhar em período integral ao mesmo tempo em que cursava a graduação durante o turno da noite, aliando-se a isto algumas dificuldades de aprendizagem, como ocorria na época em que estava na escola. Durante o tempo em que cursou o segundo grau e que posteriormente foi estudante na UFPA, trabalhou como funcionária na loja da Fundação Nacional do Índio (Funai), "ARTINDIA", onde adquiriu conhecimentos profundos sobre seres, objetos e adornos de outros povos indígenas que não os de Oiapoque (Karipuna, Palikur, Galibi Marworno e Galibi Kalinã), ao mesmo tempo em que foi estagiária na Reserva Técnica de Etnografia Curt Nimuendajú do Museu Paraense Emílio Goeldi (1987 - 1991), onde atualmente trabalha como técnica (1991 atualmente).

Suzana desejava se tornar antropóloga, para trabalhar com seu povo, porém na época não existiam universidades que ofertassem o curso no estado do Amapá. Na capital paraense, o que mais se aproximava do curso de Antropologia era o curso de Ciências Sociais e o máximo que o cacique Côco pôde realizar pelas filhas foi enviá-las para estudarem no espaço urbano de Belém, onde possuíam um acesso à educação institucional mais amplo que no estado do Amapá.

Suzana e suas irmãs migraram para os espaços urbanos, única e exclusivamente com a finalidade de irem à escola e cursarem o Ensino Superior, por mais que os reveses da vida as tenham levado também por outros caminhos por estes espaços. Em Belém, Suzana concluiu o Ensino Médio e o Superior; suas irmãs Isabel e Estela, o Ensino Secundário; e Vitória, o Ensino Superior, esta última se tornando a primeira odontóloga do povo Karipuna, assim como a primeira pessoa indígena de nosso povo a ingressar e concluir o Ensino Superior. Suzana foi a segunda pessoa de nosso povo a realizar esse 
feito, porém no curso de Ciências Sociais, e ela é provavelmente a primeira indígena a atuar em reserva técnica de etnografia no país, além de ser a primeira mulher indígena a atuar como funcionária no Museu Paraense Emílio Goeldi durante os 153 anos de existência dessa instituição (SOARES, 2018b).

Suzana conta que, principalmente no período em que fazia curso preparatório para passar no vestibular e após adentrar na universidade, evitava dizer que era indígena, pois o racismo era algo que percebia como muito forte nesses espaços. Racismo este que recai sobre as feridas coloniais (QUIJANO, 2011) e sobre a violência de gênero, pois ser mulher indígena é algo distinto de ser homem indígena em contextos de violência, já que, como aponta Segato (2014), a mulher indígena está inserida em uma condição de vulnerabilidade maior do que a que é enfrentada pelo homem indígena, enfrentando, ao mesmo tempo, um racismo por conta de sua identidade e o machismo, este último existente fora e dentro dos espaços indígenas (CURIEL, 2012; LUGONES, 2010; SEGATO, 2012).

Atualmente, dentre as filhas de Côco e Delfina, Suzana é a única que permaneceu no espaço urbano belenense, pois Isabel se mudou para a Guiana Francesa e Estela e Vitória retornaram para a aldeia. Porém, estar distante de territórios tão importantes para os povos indígenas como o são os espaços da aldeia, dos rios, das roças, das florestas e outros pontos sagrados onde habitam os karuãnas ${ }^{10}$ de nossa cosmologia é algo que pode ressignificar o que é a territorialidade para o indígena que está distante fisicamente destes espaços.

Sentir saudades da aldeia Santa Isabel é algo que sempre ouço de meus parentes Karipuna que vem à Belém, pois, após as filhas de Côco saírem, outras mulheres e homens também o passaram a fazer (por motivos de estudo ou profissional ou por tratamento de saúde). Estar na aldeia é algo que nos fortalece, pois a aldeia é o nosso principal território e, como ressaltam os indígenas Palikur, que compartilham o Uaçá conosco, "estar longe da aldeia é algo que enfraquece" (CAPIBERIBE, 2001). Como Karipuna, no que é tocante à nossa cosmologia, que em muitos pontos se assemelha ou se une a dos Palikur, percebo que assim também ocorre conosco. Nos afastar da aldeia é algo muito duro, sentimos a sua ausência e para amenizar as faltas tomamos medidas para que o distanciamento seja o menor possível, tanto geográfica, quanto temporalmente, quanto de outras formas. Pois, ao estarmos na cidade trazemos um pouco da aldeia em Oiapoque conosco, em uma tentativa de também deslocá-la, ou seja, não se deslocam apenas os nossos corpos, mas junto se desloca todo um conhecimento 
Karipuna, em uma tentativa de reajustar o bem-viver indígena do espaço da aldeia a um bem-viver indígena em um contexto urbano provisório. Todavia, ressalto que para nós, Santa Isabel é insubstituível como território indígena físico.

Porém, se o território indígena é físico, há alguns elementos que o compõem que são transponíveis e são estes que trazemos por onde passamos. São as nossas narrativas, a nossa língua, alguns de nossos rituais, a nossa cultura material e os grafismos, este último uma das mais relevantes formas dos povos indígenas se comunicarem entre as pessoas de seu grupo e com os outros seres de sua cosmologia. Um território indígena é quando nós Karipuna estamos a conviver com nossos parentes e o é também quando estamos vivenciando nossos conhecimentos. Enquanto as filhas de Côco e Delfina estiveram no espaço urbano belenense, elas teceram em meio às suas vivencias e diálogos seu próprio território Karipuna, mas sem jamais esquecer a aldeia. Portanto, a territorialidade, para nós, compreende o espaço físico da aldeia, mas também é aquilo que vai conosco para onde formos (seja se estivermos na aldeia, ou fora dela, ou em outros mundos, que são os mundos de nossas cosmovisões $\left.{ }^{11}\right)$.

É importante ressaltar que a territorialidade ser algo transcendental não invalida, de forma alguma, a nossa luta pela demarcação e preservação de nossos territórios físicos, que são fundamentais e são nossa prioridade, pois é nele que vivem as nossas populações e é onde está a nossa história ${ }^{12}$. Além disso, compreende questões de resistência aos processos de etnocídio, genocídio e ecocídio que atingem as populações indígenas ${ }^{13}$.

Suzana diz que, apesar de estar há muito tempo em Belém, não deseja viver para sempre em tal cidade, pois seu sonho é retornar à Santa Isabel. Apesar de estar geograficamente distante, ela ainda sente o conforto da territorialidade indígena, vivenciando muitos aspectos da cultura Karipuna em seu cotidiano e trabalhando no Museu Goeldi diretamente com objetos e seres da cultura material de diversos povos indígenas brasileiros. Ela também relata que, ao estar em contato com eles, sente-se fortalecida e em um espaço indígena, pois estar em contato com estes para ela é como estar em uma aldeia, trabalhar com objetos Munduruku é como estar em uma aldeia Munduruku, trabalhar com objetos Krenac é como estar em uma aldeia Krenac e assim por diante. Percebo as pesquisas antropológicas em que participo e que envolvem meu povo de maneira semelhante: nelas me sinto aproximada de meus parentes e da aldeia.

Logo, a partir de uma compreensão sobre quem foram as primeiras mulheres Karipuna a se deslocarem, para que elas se deslocaram? E como isto afeta a 
compreensão da questão territorial? Entendo que o território para nós, Karipuna, é algo físico em termos de matas, rios, aldeia e roça, mas também compreende conhecimento e contato com os parentes. O território é algo físico, mas também algo intrínseco ao nosso deslocamento, pois onde estamos levamos nossa identidade, levamos quem são os Karipuna; em nosso cotidiano, construímos as lutas e as histórias de um povo; e assim o fizeram as mulheres citadas e o fazem os indígenas que vieram após as mesmas.

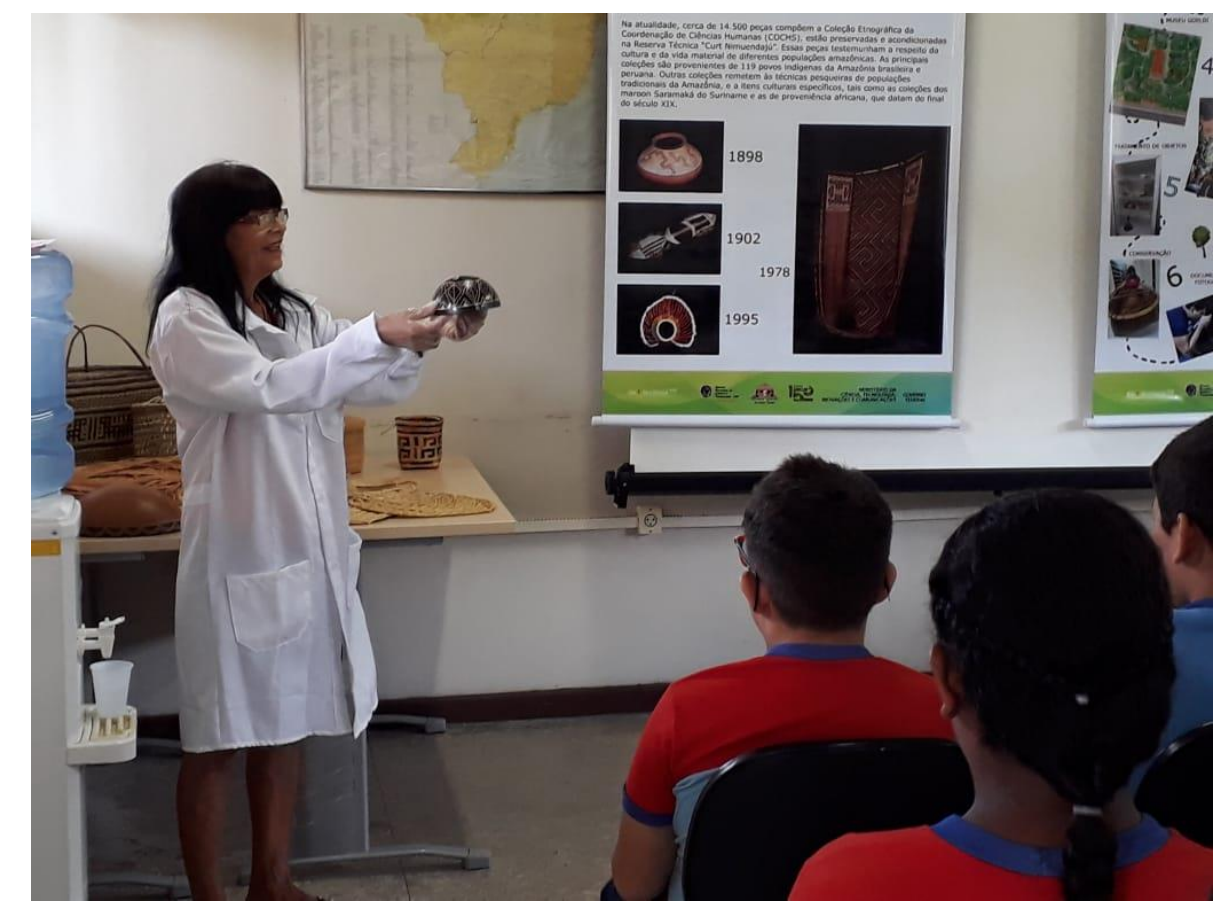

Figura 4: Suzana dos Santos Karipuna durante o evento Museu de Portas Abertas no campus de pesquisa do Museu Paraense Emílio Goeldi em 01 de novembro de 2018. Foto: Daniele Rodrigues José Peixoto.

\section{A continuidade do deslocamento: $\mathrm{Um}$ retorno para a aldeia - $\mathrm{O}$ mundo dos índios e o mundo dos brancos}

Ao estudar em Belém (PA) em uma escola não indígena e, posteriormente, ao adentrar em uma graduação em Ciências Sociais (UFPA), me deparei nestes dois espaços com um pensamento de Durkheim que diz que o fato social é algo exterior, coercitivo e generalizante; a exterioridade correspondendo ao ato daquilo estar ali antes do nascimento do indivíduo e continuar após a morte do mesmo (DURKHEIM, 1999). A partir desta questão, passei a refletir sobre o que a perspectiva da exterioridade representava para mim em minha condição de mulher indígena urbana, pois entendo meu deslocamento para o espaço da cidade, metaforicamente, como algo que é anterior ao meu nascimento, ou seja, como algo que não foi escolha minha, porém me marcará 
por toda a vida. O deslocamento é algo que sempre esteve presente em mim, ainda que eu, por muito tempo, não o percebesse de maneira tão clara. Porém, as feridas geradas por este movimento, que é anterior à minha própria existência, são algo que sempre senti e que ainda hoje irrompem em meu ser. Eu apenas não compreendia o porquê de elas existirem e estarem ali.

Quando criança, meus pais ${ }^{14}$ me diziam que eu era indígena Karipuna. Lembro que algumas vezes entre os cinco e os sete anos de idade cheguei a ir aos nossos territórios em Oiapoque - AP. Porém, vivi por muito tempo em Belém - PA e ainda vivo, em decorrência de meus estudos e do fato de que minha mãe, como já mencionado, trabalha em tal cidade. Em Belém, por medo de atos de violência, na infância e adolescência, sempre evitei dizer que era indígena, pois havia ocasiões em que, quando revelava minha identidade, as pessoas me constrangiam, dizendo de maneira autoritária: como eu poderia ser indígena se morava em cidade, não tinha a aparência e nem me trajava como uma? Isto era algo que muito me entristecia. Hoje compreendo que, em meio ao racismo, tais pessoas têm em si a imagem de um índio cristalizado, estereotipado. São não indígenas que auto reivindicam para si o veredito final de declararem quem é indígena e quem não o é. São pessoas que apenas sabem lidar com um indígena que há em sua imaginação (TOCANTINS, 2016) e que não compreendem a complexidade de um índio hiper-real, um índio de carne e osso como nos explica Alcida Rita Ramos (1988).

Até o final da adolescência, o fato de eu estar na cidade, o distanciamento da aldeia, dos parentes e o racismo eram algo que eu não conseguia compreender. Passei a entender tudo isto e a sentir um reconforto maior na minha condição de indígena no espaço universitário. Em tal local, ainda permanecem os constrangimentos e os racismos, porém nele, através da graduação em Ciências Sociais que iniciei em 2014 pela UFPA (aos 19 anos de idade) e das bolsas de Iniciação Científica em antropologia (realizada entre os anos de 2016 e 2018, no Museu Paraense Emílio Goeldi), passei a pesquisar diretamente questões correspondentes ao meu povo de origem e entre ele principalmente a mulheres indígenas. A partir desse contato na academia, eu, que só me deslocava há muito tempo pelo espaço urbano belenense, retornei à aldeia para pesquisar com os Karipuna e, ao retornar para lá, minha mãe passou a retornar junto comigo.

Todavia, este retornar para aldeia corresponde também a uma outra discussão, que é sobre como meu povo me percebe como indígena e antropóloga. Contudo, não me deterei sobre isto, ao menos ainda não neste artigo, cabendo, porém, esclarecer que 
não sou a única a ocupar esta dupla posição entre os Karipuna. Por exemplo, Tonico Benites, indígena e antropólogo Guarani Kaiowá, fala que a posição de "antropólogo indígena é uma conjunção certamente nova para a antropologia brasileira", afirmando também que: "No contexto histórico contemporâneo, os indígenas após estudarem, pesquisarem e se formarem em Antropologia não podem se desvincular tanto de seu povo pesquisado quanto de estudos antropológicos" (BENITES, 2015).

Há, pois, uma grande confiança que é depositada no antropólogo indígena por este ser alguém que, segundo Benites, compreende a história e a luta de seu povo ao mesmo tempo em que pesquisa em prol das demandas de seu coletivo. Logo, ser antropólogo indígena é assumir uma posição de responsabilidade, pois este é visto como alguém que auxilia na solução dos problemas, sendo que o que realiza é tanto monitorado pelos próprios indígenas quanto por pessoas não indígenas (BENITES, 2015).

Este estar com alguns de meus parentes, primeiro em Belém, depois na aldeia; conversar com minha mãe sobre nossos conhecimentos, mas também com os outros Karipuna; escrever, fotografar e desenhar nossas vivências é para mim uma forma de resistência da nossa identidade, dos nossos conhecimentos e da nossa territorialidade. Fazer isto é uma retomada de memória. Como já expresso, não tive quase convívio na aldeia quando criança e adolescente, algo díspar do que acontece agora em minha vida adulta. Portanto, não vivi muitos momentos importantes para uma menina e uma adolescente Karipuna. Escrever sobre as mulheres é uma maneira de retomar essa vivência. $\mathrm{O}$ deslocar se iniciou quando algumas indígenas Karipuna vieram para Belém estudar e eu agora faço o caminho contrário, também para estudar, mas com vistas acima de tudo a estar com meu povo, a conhecer e a refletir sobre quem somos, a pensar esta antropologia que nos põe na posição de objetos, informantes, interlocutores, quando somos os donos e/ou autores de tais conhecimentos. Entendendo-se por fim que deslocar nem sempre é se distanciar. Ao se deslocar, muitas vezes se leva consigo uma bagagem pesada e o deslocar por muitas das vezes pode significar estar perto ou retornar em algum momento.

\section{Considerações finais}

Em meio ao recorte de gênero, busquei aqui expressar um pouco de como se deu a saída das mulheres indígenas Karipuna para fora das aldeias. Não que antes outras 
mulheres não tenham saído para estar em outros locais, isso muito provavelmente ocorreu, principalmente por conta dos casamentos exogâmicos com homens de outros grupos indígenas e com não indígenas. Todavia, essa saída (por qual motivo fosse) não era algo comum, até mesmo para os homens, passando a se tornar mais natural a partir do momento em que o cacique de Santa Isabel e dos Karipuna do Amapá passou a incentivar as filhas aos estudos e a financiar suas saídas da aldeia com esta finalidade. As mulheres migraram com o objetivo de estudarem e até hoje este mesmo objetivo permanece com a maioria das mulheres e homens indígenas que vem a Belém - PA, ressaltando-se que poucos são os que estão aqui por motivo de trabalho: a maioria vem para estudar na Universidade Federal do Pará e, após isto, geralmente retornam para a aldeia, havendo atualmente cerca de dez indígenas Karipuna, distribuídos entre cursos de graduação e pós-graduação na UFPA.

$\mathrm{O}$ fato de as primeiras pessoas fora da aldeia serem mulheres abre espaço para se pensar as formas de protagonismo feminino Karipuna. Em meu povo, apesar de termos sido consideradas pessoas de caráter retraído e tímido, nós mulheres sempre tivemos nossos protagonismos, que antigamente vinham principalmente sobre as formas de fundadoras de aldeias, pajés e parteiras e hoje se multiplicam pelos papeis de caciques, vice caciques, conselheiras, professoras, funcionárias públicas e universitárias.

A saída das mulheres, além de um olhar sobre o protagonismo feminino indígena, também é um olhar sobre o processo educacional em nível superior. Os indígenas Karipuna que atualmente o estão cursando, além dos mencionados na UFPA, também se encontram em outras universidades e faculdades, tais como a Universidade Federal do Amapá e a Universidade de Brasília. Denota-se assim que, para nós Karipuna, estar na universidade é uma posição política. $\mathrm{O}$ indígena que está no espaço acadêmico está a tomar conhecimento do mundo dos não indígenas, mas não de forma a substituir os seus conhecimentos, mas sim de maneira a complementar seus saberes e a dialogar com este outro mundo. Nós, no espaço acadêmico, estamos: a lutar pelos nossos direitos de acesso à educação, saúde, demarcação e proteção dos nossos territórios; a aprender a nos defender dos ataques dos não indígenas por meio da compreensão das ferramentas de violência jurídicas e políticas das quais eles se utilizam para nos atacar; e também o utilizamos como uma via para termos mais acesso à participação nos processos e tomadas de decisões que nos envolvem, visto que uma parcela dos não indígenas são insistentes no que diz respeito à tomada de decisões sem consulta prévia aos protocolos dos povos indígenas. 
Logo, o conhecimento indígena produzido na academia é, para nós indígenas, algo diferenciado do que advém da aldeia, porém também de suma importância. Para a universidade, nós trazemos a aldeia e, dentro dos limites do necessário, o contrário, mas de modo que a própria aldeia, a identidade e os conhecimentos indígenas se fortaleçam nestes percursos.

Quando mencionei que iria me ater mais aos deslocamentos de nível micro ao invés dos deslocamentos de nível macro (SIMMEL, 2006), considerei o fato de que o deslocamento e a estada de indígenas, mulheres ou homens, por locais urbanos é algo que perpassa pelo contexto de diversos povos indígenas e que se dão por inúmeros motivos (macro). Porém, aqui me debrucei sobre uma das realidades de meu povo (micro), que é apenas uma das múltiplas realidades de ser indígena em contexto urbano, visto que nós indígenas em muito nos assemelhamos, em decorrência de nossas lutas e pautas políticas, mas também em muito nos diferimos, pois ser indígena de um povo traz características distintas da de ser indígena em um outro.

Ressalte-se que a identidade é um acontecimento, não é algo fixo e imóvel. Não indígenas que se embasam sobre ideias racistas utilizam-se da noção de que indígenas em contexto urbano não são mais indígenas. Todavia, permanecemos indígenas por onde estivermos. Identidade, território e conhecimento também são acontecimentos e se ressignificam e cabe aos próprios povos atribuírem os critérios para tais identidades, territorialidades e questões derivadas das mesmas.

Aqui, conectei o particular ao social (MILLS, 1975), pois a questão do deslocamento de minhas parentas repercute sobre a história de nosso povo. Além disso, o texto converge para o fato de que é importante ler e ouvir o que o indígena tem a dizer sobre as próprias questões, pois, como aponta Curiel (2012), as ciências sociais possuem um compromisso ético de oferecer ferramentas para que os cientistas sociais latino americanos expliquem as suas realidades, na tentativa de se superar um olhar hegemonicamente branco que há nas ciências sociais.

As mulheres Karipuna se deslocam atualmente, principalmente, pela questão concernente à educação em nível superior. Dificilmente os motivos são outros, mas eles ocorrem. Porém, em meio a estes ir e vir, nós, povo Karipuna, prosseguimos na luta pela manutenção de nossos territórios fixos e transponíveis, ou seja, respectivamente, de nossas Terras Indígenas e do conhecimento que levamos conosco. Nós, quando trasladamos pelos espaços urbanos, não esquecemos quem somos, estamos conectadas ao povo e a aldeia. 


\section{Notas}

${ }^{1}$ O povo Karipuna do Amapá é um povo indígena que, apesar do etnônimo, não possui vínculos com o povo Karipuna de Rondônia. Ambos são povos que possuem língua, história, cosmologia e conhecimentos distintos.

2 Segundo dados do Instituto Sócio Ambiental (ISA), registrados em 2014 pelo Sistema de Informação da Atenção à Saúde Indígena (SIASI), através da Secretaria Especial de Saúde Indígena (SESAI).

Fonte: https://pib.socioambiental.org/pt/Povo:Karipuna_do_Amap\%C3\%A1. Acesso em: 10 mai. 2019

${ }^{3}$ Os Galibi Kalinã do Brasil também são conhecidos como Galibi do Oiapoque (CAPIBERIBE, 2001).

${ }^{4} \mathrm{O}$ patuá pode ser chamado e grafado patoá ou patois ou créole ou kheoul. De acordo com Tassinari (2015, p. 68) "seguindo a grafia para línguas indígenas no Brasil, para sua utilização nas escolas indígenas, passou a ser grafada como khenol”. Enquanto Machado (2017. p. 28, 52) diz que o "khenol falado pelos Galibi Marworno e o patuá ou patoá falado pelos Karipuna são a mesma língua, com pequenas diferenças fonéticas entre si, e são variações do crioulo "negro" falado na Guiana Francesa", sendo que estes dois povos o adotaram como sua língua usual. Capiberibe (2001, p. 17) define o patuá como um dialeto originário do francês. Porém, Montejo (1988) fala do kbeuol "como a língua materna dos índios Karipuna e Galibi Marworno, sendo o patuá falado também na Guiana Francesa". Afirmando ainda que "o patuá é uma língua crioula", porém, negando que o "khenol ou patuá seja um dialeto ou uma espécie de "francês mal falado", pois, de acordo com esta autora o khenol se constituiu ao longo dos séculos como verdadeira língua indígena" (MONTEJO, 1988, p. 4, 5, 8). O kheuol ou patuá no catálogo da Europalia Índios no Brasil (KARIPUNA, 2011/2012) é definido por Suzana Primo dos Santos, indígena Karipuna, como "uma mistura de francês e dialetos das famílias indígenas da região de Oiapoque". Contudo, me referirei a língua falada por nós Karipuna somente como patuá, por ser este o termo e grafia mais utilizado por meu povo.

${ }^{5}$ A Terra indígena Uaçá foi demarcada e homologada por decreto presidencial em outubro de 1992. Ela abrange os rios Urukauá e Curupi, tendo superfície de 470.164,0636 hectares e perímetros de 278.139,44 metros. Porém, a aldeia Santa Isabel que está dentro desta Terra Indígena é anterior a existência dela, uma vez que foi fundada na década de 1940 (Tassinari, 2003), informação que aparece no decorrer do texto.

6 "Parente" é um termo que pessoas indígenas, no Brasil, se utilizam para se referir a outras pessoas também indígenas, sejam estas pessoas oriundas de seu povo ou de algum outro povo indígena". 
${ }^{7}$ Assis começou a realizar pesquisas de campo conosco na década de 1970 (ASSIS, 1981, 2012). Observando que até meados da 1990 as mulheres Karipuna eram muito retraídas para com os não indígenas, algo que é confirmado pelas mulheres mais velhas de meu povo.

${ }^{8}$ Não há um consenso sobre o ano exato em que a aldeia Santa Isabel foi fundada, tendo-se apenas certeza da década em que isto ocorreu.

${ }^{9} \mathrm{O}$ nome da aldeia é em homenagem a filha mais velha do casal fundador, que já era nascida quando a aldeia foi fundada. Trazendo em seu nome além da homenagem a influência católica que os Karipuna possuem.

${ }^{10}$ De acordo com o livro Turé dos povos indígenas de Oiapoque (TURÉ, 2009. p. 11) "Os karuãna ou bichos são pessoas que vivem no Outro Mundo, onde são gente como nós, e que apenas os pajés conseguem ver e se comunicar com eles. Vêm do mar, dos rios, lagos, das matas e do espaço e são espíritos de aves, cobras, peixes, árvores e estrelas. Os karuãnas que vivem na água são geralmente Cobras Grandes de uma, duas ou até três cabeças e Sereias (Mamã dijlô). Os da floresta são Djab dã bua, como o anão cabeludo Hoho, o Curupira (Yaddeges), a Matintaperera (Maksilili/Mammatki) e Jurupari (Yorokãn). Os que vêm do espaço são considerados grandes médicos e doutores que curam as doenças das pessoas visíveis através dos pajés, como Laposiniê (conhecida em português como Sete Estrelas). Mas os karuãna também provocam doenças e até matam. Há ainda karuãnas que já viveram no nosso mundo, como Yakaikani, e depois se encantaram e viraram Bichos e outros que gostam de ter filhos com as mulheres visíveis, como a Cobra Kadaikaru e o Jacaré. Os karuãna ou bichos do mundo invisível são grandes médicos, doutores, cientistas, pessoas como nós que durante o turé são convidadas pelo pajé para participar da festa, tomar muito caxixi e fumar os grandes cigarros de tawari” (TURÉ, 2019. p. 19).

${ }^{11}$ A cosmologia Karipuna do Amapá de maneira geral divide o universo em três dimensões: $\mathrm{O}$ Mundo dos seres humanos, que é o Mundo dos homens; o Outro Mundo que é o Mundo dos bichos e karuãnas; e O Mundo dos mortos.

12 Meira (2018, p. 59) ao se reportar ao Noroeste Amazônico (região distante do Baixo Oiapoque), nos diz que os territórios indígenas "são o todo formado pelos seres vivos e as coisas inanimadas, como as águas, as pedras, a terra. Nesse sentido, o território se define pelas relações dinâmicas e recíprocas dos povos e seus subgrupos entre si, e entre estes e os ambientes 'natural' e 'sobrenatural'. Trata-se de territórios construídos e ordenados social e cosmologicamente...", complementando que o território é também determinado pela toponímia e pela organização social. (MEIRA, 2019, p. 82).

${ }^{13}$ Manifesto do 3o Congresso Internacional Povos Indígenas da América Latina: "Aqui estamos resistindo a um processo de etnocídio, genocídio e ecocídio que não termina. Nossas forças espirituais nos guiam para defender a Mãe Natureza" ( $3^{\circ}$ Congresso Latino Americano de Povos Indígenas da América Latina. Brasília, Brasil, 5 de julho de 2019).

${ }^{14}$ Apenas minha mãe, Suzana, é indígena Karipuna. Meu pai é um não indígena. 


\section{Referências}

ARNAUD, Expedito. O sobrenatural entre os índios do rio Uaçá (Oiapoque Amapá) Palikúr, Galibí do Uaçá e Karipúna. Anais da II Reunião de Antropólogos do Norte e Nordeste. Org. R. Parry Scott. Recife. 1991.

ARNAUD, Expedito. O xamanismo entre os índios da região Uaçá (Oiapoque Território do Amapá). Belém: Boletim do Musen Paraense Emílio Goeldi, Antropologia, 1970. p. 1-26. Disponível em: http://repositorio.museugoeldi.br/bitstream/mgoeldi/944/1/B\%20MPEG\%20Ant\%20n44\%201970\%20ARNA UD\%20ri.PDF Acesso em: 31/05/2019.

ASSIS, Eneida Corrêa de. Escola Indígena, uma "frente ideológica"?. Dissertação de mestrado apresentada ao programa de pós-Graduação em antropologia social da Universidade de Brasília. Brasília, 1981.

ASSIS, Eneida Corrêa de. Descobrindo as Mulheres Indígenas no Uaçá Oiapoque: uma antropóloga e seu diário de campo. In: Gênero na Amazônia. UFPA. Belém, n. 1, jan/jun,. 2012.

BENITES, Tonico. Os antropólogos indígenas desafios e perspectivas. Novos debates. Fórum de debates em antropologia. 2015. Disponível em: http://novosdebates.abant.org.br/index.php/numeros-anteriores/v2n1/opiniao/139v2-n1/opiniao/195-os-antropologos-indigenas-desafios-e-perspectivas. Acesso em 24 de out. de 2019.

CAPIBERIBE, Artionka Manuela Góes. Os Palikur e o Cristianismo. Orientador: Robin Michel Wright. Coorientadora: Lux Boelitz Vidal. Dissertação (Mestrado). Universidade Estadual de Campinas, Instituto de Filosofia e Ciências Humanas 2001.

CARDOSO DE OLIVEIRA, Roberto. O indio e o mundo dos brancos. DIFEL. 1964.

CURIEL, Ochy. Género, raza y sexualidad. Debates contemporâneos, 2012

DIAS, Letícia Otero. O feminismo decolonial de María Lugones. http://eventos.ufgd.edu.br/enepex/anais/arquivos/318.pdf. · Arquivo PDF.

DICIONÁRIO KHEUOL X PORTUGUÊS PORTUGUÊS X KHEUOL. NO DJISONE KHEUOL - PORTXIGE. O NOSSO DICIONÁRIO PORTUGUÊS KHEUOL. Povos Karipuna e Galibi Marworno. Organização de Francisca Picanço Montejo. Edições Mensageiro. 1988.

DURKHEIM, E. Da Divisão do Trabalho Social. SP: Martins Fontes, 1999.

GOMES, Camilla de Magalhães. Gênero como categoria de análise decolonial. Civitas. Revista de Ciências Sociais. v. 18, n. 1. 2018.

HERITIER, Françoise. Masculino Feminino / II: Dissolver a hierarquia. Trad. Carlos Abraim de Brito. Instituto Piaget. Lisboa. 2002. 
LÓPEZ GARCÉS, Claudia Leonor; SANTOS [KARIPUNA], Suzana Primo dos. Passado e presente dos povos indígenas no Museu Goeldi: conhecimentos indígenas e documentação do acervo etnográfico. Evento: $O$ entrelaçamento entre bumanos e coisas: Participação e transformações". Bonn. Alemanha. 2017. Manuscrito inédito.

LUGONES, Maria. Rumo a um feminismo descolonial. Revista Estudos Feministas. Artigo originalmente publicado na revista Hypatia, v. 25, n. 4, 2010.

MACHADO, Tadeu Lopes. 2017. Na cidade vendo a farinha e de lá trago mercadoria e dinheiro para a aldeia: redes de sociabilidades e intercâmbio de bens dos indígenas Palikur na Cidade de Oiapoque - AP. Dissertação (Mestrado) - Programa de PósGraduação em Sociologia e Antropologia, do Instituto de Filosofia e Ciências Humanas, da Universidade Federal do Pará. 2017. Manuscrito inédito.

MALDONADO-TORRES, Nelson. Sobre la colonialidad del ser: contribuciones al desarrollo de un concepto. In: El giro decolonial: reflexiones para una diversidad epistémica más allá del capitalismo global. Bogotá: Siglo del Hombre Editores; Universidad Central, Instituto de Estudios Sociales Contemporáneos y Pontificia Universidad Javeriana, Instituto Pensar, pp. 127-168. 2007.

Manifesto do 3o Congresso Internacional Povos Indígenas da América Latina: Aqui estamos resistindo a um processo de etnocídio, genocídio e ecocídio que não termina. Nossas forças espirituais nos guiam para defender a Mãe Natureza. $3^{\circ}$ Congresso Latino Americano de Povos Indigenas da América Latina. Brasília, Brasil, 5 de julho de 2019.

MEIRA, Márcio. A persistência do aviamento: colonialismo e história indígena no Noroeste Amazônico. São Carlos. EduFSCar, 2018.

MIGNOLO, Walter D. La idea de América Latina. La herida colonial y la opción decolonial. Barcelona, Editorial Gedisa, 2007.

MILLS, Charles Wright. A imaginação sociológica. Zahar, 1975.

NASCIMENTO JÚNIOR, Wanderley dos Reis. O paradigma do "vivir bien" no estado plurinacional da Bolívia como referente para a construção de políticas públicas emancipatórias. Revista Brasileira de Políticas Públicas e Internacionais, v.1, n.1, pp.212-234. jun-ago. 2016.

POVOS INDÍGENAS NO BRASIL / (coordenador geral Carlos Alberto Ricardo). Vários colaboradores. São Paulo: CEDI. v.3 Amapá e Norte do Pará. 1983.

QUIJANO, Aníbal. "Bien vivir": entre el "desarrollo" y la des/colonialidad del poder. Viento Sur, n. 122, mai. 2012.

QUIJANO, Aníbal. Colonialidad del poder y subjetividad en América Latina. Contextualizaciones. Revista semestral del Departamento de Estudios Ibéricos y Latinoamericanos de la Universidad de Guadalajara. Año 3, número 5, jul/dic. 2011.

RAMOS, Alcida Rita. O índio hiper-real. Seminário sobre Ética e Antropologia. Rio de janeiro. 1988. 
RAPPAPORT, Joanne. A institucionalização da pesquisa indígena: Desafios na Colômbia. In: Interculturalidade(s): entre ideias, retóricas e práticas em cinco países da América Latina / organização de Antonio Carlos de Souza Lima, Luis Felipe dos Santos Carvalho, Gustavo Lins Ribeiro. - Rio de Janeiro: Associação Brasileira de Antropologia; Contra Capa, p. 181-200, 2018.

RAPPAPORT, Joanne. Más allá de la escritura: la epistemología de la etnografía en colaboración. Revista Colombiana de Antropología. Volumen 43, pp. 197-229, enero/dic. 2007.

RONDON, Marechal, 1865-1958. Índios do Brasil. Brasília: Senado Federal, Conselho Editorial, 2019.

SANTOS, Ariana dos; MACHADO, Tadeu Lopes. As mulheres no movimento indígena de Oiapoque: uma reflexão a partir da associação das mulheres indígenas em mutirão. Espaço Ameríndio, Porto Alegre, v. 13, n. 1, p. 67-86, jan./jun. 2019.

SANTOS [KARIPUNA], Suzana Primo dos. Calebasse "cuia" Karipuna. In: Índios no Brasil. França. Europalia. (2011/2012).

SANTOS SILVA, Luiz Wallac Oliveira dos. A relação entre as fontes de renda e as atividades produtivas na aldeia Santa Izabel, Terra Indígena Uaçá, no município de Oiapoque. Trabalho de Conclusão de Curso (Curso de Licenciatura Intercultural Indígena) Universidade Federal do Amapá, Oiapoque, 2018.

SEGATO, Rita Laura. El sexo y la norma: frente estatal, patriarcado, desposesión, colonialidad. Estudos Feministas, Florianópolis, 22(2): 304, mao. 2014.

SEGATO. Rita Laura. Gênero e colonialidade: em busca de chaves de leitura e de um vocabulário estratégico descolonial. e-cadernos Epistemologias feministas: ao encontro da crítica radical. 2012.

SILVA, Arivanete Oliveira da; COSTA, Johnata Dias Silva Azevedo da; ESTEVES, Vitória Santos. A organização política das mulheres indígenas do Amapá. Anais do I Encontro de Discentes de História da UNIF AP. 2017.

SIMMEL, Georg. O âmbito da sociologia. In: Questões fundamentais da sociologia. Rio de Janeiro: Ed Zahar, 2006.

SOARES [KARIPUNA], Ana Manoela Primo dos Santos. Mulheres Karipuna do Amapá: Trajetórias de Vida das Fam-Iela: Uma Perspectiva Autoetnográfica. Trabalho de Conclusão de Curso (Graduação) - Universidade Federal do Pará, Belém. 2018. Manuscrito inédito.

SOARES [KARIPUNA], Ana Manoela Primo dos Santos. Suzana Karipuna: A primeira mulher indígena no Museu Paraense Emílio Goeldi. $31^{\circ}$ Reunião Brasileira de Antropologia. Grupo de Trabalho 43: Memórias Indígenas e experiencias de construções biográficas. Universidade de Brasília, Brasília. 2018b. 
SOUZA SILVA, José de. La pedagogia de la felicidade em uma educación para la vida. El paradigma del "buen vivir"/"vivir bien" y la construcción pedagógica del "día después del desarrollo". In; WALSH, Cahterine y lo decolonial. Lo pedagógico e lo decolonial. Entretejiendo caminos (editora). Pedagogías decoloniales: prácticas insurgentes de resistir, (re)existir y (re)vivir. Tomo I. Quito, Ecuador: Ediciones AbyaYala, 2013.

STRATHERN, Marilyn. O efeito etnográfico. São Paulo. Cosac: Naify. 2015.

TASSINARI, Antonella Maria Imperatriz. A casa de farinha é a nossa escola: Aprendizagem e cognição Galibi Marworno. Politica \& Trabalho. Revista de Ciências Sociais, 43, 65-96. 2015.

TASSINARI, Antonella Maria Imperatriz. No bom da festa. O processo de construção cultural das famílias Karipuna do Amapá. São Paulo: Edusp. 2003.

TOCANTINS, Raimundo de Araújo. Iconografia e identidades: o discurso da imagem na construção do sujeito indígena. Anais do II Encontro de Antropologia Visual da América Amazônica. Belém. 2016.

TROUILLOT, Michel-Rolph. Transformaciones globales: La antropologia y el mundo moderno. Traducción y presentación: Gnecco, Cristóbal. Editorial Universidad del Cauca/ CESO, Universidad de los Andes. 2011.

TURÉ dos povos indígenas do Oiapoque. Rio de janeiro, São Paulo: Museu do Índio. Fundação Nacional do Îndio, IEPÉ. 2009.

WALSH, Cahterine y lo decolonial. Lo pedagógico e lo decolonial. Entretejiendo caminhos. In: WALSH, Catherine (Ed.). Pedagogias decoloniales: prácticas insurgentes de resistir, (re)existir y (re)vivir. Tomo I. Quito, Ecuador: Ediciones AbyaYala, 2013.

ZORZETTO, Ricardo. O irmão do norte. In: Edição Especial: Museus em crise. Revista Pesquisa FAPESP. São Paulo. Ano 19. n²72. Outubro de 2018. 